\title{
Test of the Health Promotion Model as a Causal Model of Construction Workers' Use of Hearing Protection
}

\author{
Sally L. Lusk, ${ }^{1}$ David L. Ronis, ${ }^{12}$ Mary M. Hogan ${ }^{1}$ \\ ${ }^{1}$ School of Nursing, University of Michigan, Ann Arbor, MI 48109 \\ ${ }^{2}$ Health Services Research and Development Program, Department of Veterans Affairs, \\ Ann Arbor, MI 48109-0482 \\ Received 22 June 1995; accepted 25 November 1996
}

\begin{abstract}
The health promotion model (HPM) was tested as a causal model of construction workers' use of hearing protection $(N=359)$. Theoretical and exploratory models fit well, with the theoretical model accounting for $36.3 \%$ of variance and the exploratory model accounting for $50.6 \%$ of variance in hearing protection use. Value of use (benefits of using hearing protection), barriers to use, and self-efficacy were significant predictors in both the theoretical and exploratory models, but perceived health status was a predictor only in the theoretical model. In the exploratory model, where modifying factors were allowed direct relationships with use of hearing protection, two modifying factors - noise exposure and interpersonal influences-modeling - were significant predictors. Results of this test of the HPM are consistent with the revised HPM (Pender, 1996). There were significant direct paths from modifying factors to behavior. Use of hearing protection was best predicted by behavior-specific predictors, such as perceived barriers to use of hearing protection. Results support the use of the HPM to predict use of hearing protection. (1) 1997 John Wiley \& Sons, Inc. Res Nurs Health 20: 183-194, 1997
\end{abstract}

Keywords: health promotion model; construction workers; hearing protection; model testing; preventing hearing loss

Hazardous noise is an important occupational health problem because it leads to hearing loss and may lead to increased stress and other deleterious physiological effects (Cohen \& Weinstein 1980; DeJoy 1984; Sloan, 1991; van Dijk, Souman, \& deVries 1987). More than 30 million workers are exposed to hazardous noise on the job (National Institute for Occupational Safety and Health, 1996). Use of hearing protection devices (HPDs), specifically ear plugs and/or ear muffs, is known to reduce noise exposure and prevent noiseinduced hearing loss (Sataloff \& Sataloff, 1986; Savell \& Toothman, 1987). Although there is no comprehensive data base available regarding the extent HPDs are used by workers exposed to high noise, in our previous study factory workers had entirely inadequate observed and self-reported mean usage of 54 to $62 \%$ (Lusk, Ronis, \& Baer, 1995). The sample of construction workers in the present study self-reported even lower mean usage of 18 to 49\% (Lusk, Kerr, \& Kauffman, 1996). There are, however, relatively few investigators who have examined factors related to the low use of hearing protection by workers.

In a prior study (Lusk, Ronis, Kerr, \& Atwood, 1994) we identified several factors influencing factory workers' use of hearing protection. However, these factors may not apply equally to construction workers. Construction workers differ from factory workers in several ways, particularly number: $\mathrm{OH} 03136$. 
in having the highest rates of work-related injury and illness in the United States (U.S. Bureau of the Census, 1995). They frequently work in rapidly changing work sites with exposure to noise from equipment and from the environment, while a factory environment is more static. In addition, construction workers have relatively little control over their environment. Therefore, noise exposure on construction sites is not as amenable to engineering controls as in the manufacturing sector. Coupled with this lack of control is the mobility of construction workers. Many do not consistently work with one firm or at one location, and some are relatively independent contractors. In the case of the former, hearing protection needs, policies, and availability may change rapidly for the worker, up to several times a day. In the case of the worker as an independent contractor, the individual may be the one who is both deciding whether hearing protection is needed and obtaining hearing protection equipment. Thus, use of this type of protective equipment by construction workers requires taking more personal responsibility for safety and health than may be necessary in a factory setting. Although the Occupational Safety and Health Administration mandates Hearing Conservation Programs for factory workers (OSHA, 1981), it has not yet developed a standard to require Hearing Conservation Programs for construction workers.

Because individual action in using hearing pro- tection is a useful method to reduce noise exposure (Abel, Alberti, Haythornthwaite, \& Riko, 1982; Berger, 1980) when engineering controls cannot, the purpose of this study was to test Pender's (1987) health promotion model (HPM) as a causal model to understand the use of hearing protection by construction workers. This model, derived from social learning theory, attempts to explain individuals' participation in health-promoting behaviors and posits that cognitive-perceptual factors influence health-promoting behavior. Modifying factors also may operate through the cognitive-perceptual factors in affecting behavior. The cognitive-perceptual factors consist of importance of health, perceived control of health, perceived self-efficacy, definition of health, perceived health status, and perceived benefits of and perceived barriers to health-promoting behaviors. With the exception of the perceived barriers to health promoting behaviors, all of these factors are expected to be positively related to the behavior. Modifying factors include demographic and biologic characteristics, interpersonal influences, and situational and behavioral factors. The HPM as tested in this study is illustrated in Figure 1.

Discussion of the conceptual underpinnings of the HPM and research on the model is detailed in Lusk, Ronis, Kerr, and Atwood (1994); this discussion is summarized below. Thus far, the HPM has been tested as a causal model in four studies, with varying results (Johnson, Ratner, Bottorff, \&

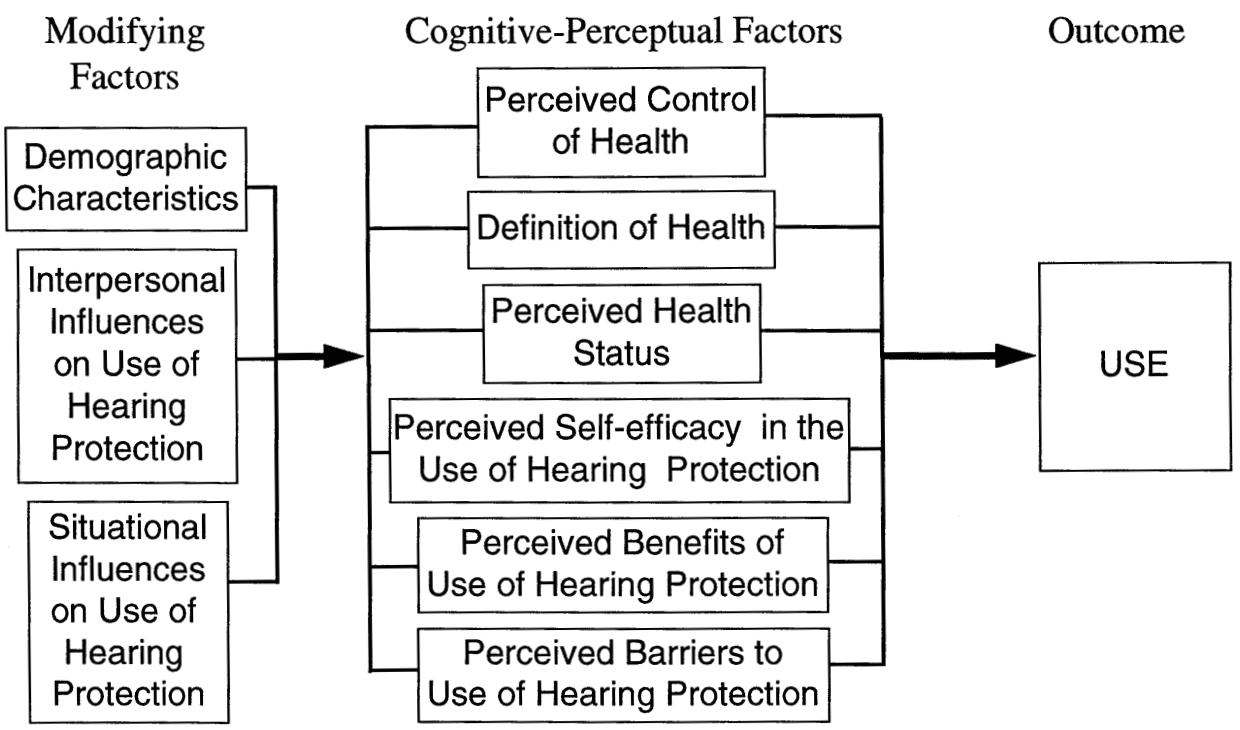

FIGURE 1. Pender's health promotion model as used in the present study. Adapted (with permission) from Health promotion in nursing practice (2nd ed.), by N. J. Pender, 1987, Norwalk, CT: Appleton \& Lange. 
Hayduk, 1993; Lusk et al., 1994; Pender, Walker, Frank-Stromborg, \& Sechrist, 1990; Ratner, Bottorff, Johnson, \& Hayduk, 1994).

Pender et al. (1990) found, with one exception, that all the proposed paths in the HPM were significant predictors of exercise performance in one or more of their four samples: working adults, older adults, cancer patients, and patients in cardiac rehabilitation. In our earlier research (Lusk et al., 1994), the HPM was examined in relation to the use of hearing protection among automotive factory workers. Results were similar to those found by Pender et al. (1990). Causal modeling of the use of hearing protection among 645 factory workers resulted in an excellent fit of the HPM and accounted for up to $53 \%$ of the variance in use of hearing protection. Self-efficacy, low perceived barriers, and benefits consistently had positive effects on use. An unexpected finding was a negative relationship between perceived control of health and use of hearing protection. This result was contrary to the expectation that there would be greater use of hearing protection by those who felt in control of their health.

Johnson et al. (1993) and Ratner et al. (1994) used data from the National Survey of Personal Health Practices and Consequences, from which they selected single items to measure concepts in the HPM. The indirect effects of two groups of modifying factors (demographic and biologic characteristics) on health-promoting behavior through three mediating cognitive-perceptual factors (perceived control of health, perceived selfefficacy, and perceived health status) were assessed. Results showed that several factors in each of the two groups of modifying factors had direct rather than indirect effects on health-promoting behaviors; thus, the original version of the HPM without direct paths from modifying factor to behavior was inadequate in explaining these behaviors.

In testing for gender differences in general health practices, Ratner et al. (1994) used four modifying demographic factors (age, family income, marital status, and education), one modifying biological characteristic (body mass index), and the same three cognitive-perceptual factors used by Johnson et al. (1993). Although they found some differences in the likelihood of engaging in health-promoting behaviors by gender, those differences did not operate through the cognitive-perceptual variables as the HPM posits. These authors found the explanatory power of the HPM poor in both above studies and, therefore, questioned the model's validity.

While these two studies do not support the
HPM, their limitations should be considered. Typically, HPM concepts have been measured with multi-item measures, rather than the primarily single-item measures used in these two studies. Only three of the cognitive-perceptual variables were included, rather than the seven in the HPM. In addition, the HPM was designed to predict specific health behaviors, such as exercise and hearing protection, rather than global health promoting actions.

In our prior research (Lusk et al., 1994; Lusk, Kerr, \& Baer, 1995), the HPM was helpful in examining a specific behavior, the use of hearing protection by factory workers. The HPM was selected because use of hearing protection, like health promoting behaviors, is under the control of the individual and requires continuous, long-term action. In addition, in other studies relationships have been found between individual components which, at that time, were unique to the HPM (such as perceived control and self-efficacy) and protective or disease preventing behaviors including use of seat belts (Langlie, 1977) and smoking reduction (Strecher, Becker, Kirscht, Eraker, \& Graham-Tomasi, 1985). Further, because our present study was focused on the same health behavior, hearing protection, with a different worker population, the continued use of the HPM was appropriate.

One cognitive-perceptual factor from the HPM, importance of health, was not included in this study because it has not had sufficient variance in other studies to be useful as a predictor. This factor has not been included in the revised model (Pender, 1996) which was published after this study was undertaken. Two modifying factors, behavioral factors and biological characteristics, were not used in this test of the HPM. These components typically have not been used in other tests of the HPM, making them more difficult to operationalize with reference to hearing protection use. Minimizing respondent fatigue also was a factor that required limitation to variables that were most crucial.

\section{METHOD}

\section{Sample}

Midwestern carpenters, operating engineers, and plumbers/pipefitters were recruited through trade unions and trade group associations to participate in the study. Trainees and apprentices, as well as experienced workers in the three trades, were included. Written questionnaires were completed by 
the participants in classroom settings as they attended journeyman and refresher courses provided by their trade groups.

Subjects were recruited through contacts with trade union locals $(N=12)$ in the Midwest who arranged for data to be collected during their ongoing classes. Less than $2 \%$ of the class members either refused to sign the consent form to participate in the study or signed the form but failed to complete the questionnaire. A total of 359 persons were included in these analyses: 119 operating engineers, 111 carpenters, and 129 plumbers and pipefitters. As indicated in Table 1, the vast majority were male (94\%) and Caucasian (87\%), with about $8 \%$ African American. The mean age (33 years) differed by group, with the operating engineers the oldest and the carpenters the youngest. Nearly all the workers had at least a high school diploma (95\%), but carpenters and plumbers/pipefitters were more likely to have had some formal education beyond high school than operating engineers. About 55\% of the total group were married, but there were differences by trade with a much larger proportion of the operating engineers married and a smaller proportion of carpenters married. The mean number of years in the trade also differed among the groups, with the older operating engineers having more years than the younger plumbers and carpenters.

As shown in Table 1, operating engineers had the highest proportion of work time spent in high noise, and plumbers/pipefitters the lowest. The percent of time that workers wore hearing protec- tion when exposed to high noise was not entirely consistent with exposure. The operating engineers with the highest exposure also had the highest use, but plumbers/pipefitters who had the lowest exposure had a higher use than carpenters. Overall, $24 \%$ of the workers never used hearing protection when exposed to high noise, and $5.3 \%$ always wore hearing protection when exposed.

\section{Measures}

The concepts utilized in the study, instruments used to measure the concepts, mean scores, and theta reliability coefficients for the whole sample are listed in Table 2. All the scales had acceptable reliability of at least .70 for this sample. The instruments had been used with worker populations in previous studies with acceptable reliability (Lusk, Ronis, \& Baer, 1995). Conceptual and operational definitions of the model components and examples of items included in the scales measuring the components follow. Unless otherwise indicated, all measures had a 6-point Likert-type scale from strongly disagree to strongly agree. Questionnaires were prepared in a booklet format and typically required an average of 35 to $40 \mathrm{~min}$ to complete.

Noise exposure was assessed with a series of questions about time on the job exposed to "high noise" over the last week, month, and 3 months. High noise was defined as "when you have to shout to be heard by a coworker who is 3 feet or less away from you."

Table 1. Demographics, Noise Exposure, and Hearing Protection Use by Trade Group

\begin{tabular}{|c|c|c|c|c|c|c|}
\hline & \multicolumn{2}{|c|}{$\begin{array}{l}\text { Operating } \\
\text { Engineers } \\
(n=119)\end{array}$} & \multicolumn{2}{|c|}{$\begin{array}{l}\text { Carpenters } \\
(n=111)\end{array}$} & \multicolumn{2}{|c|}{$\begin{array}{l}\text { Plumbers/ } \\
\text { Pipefitters } \\
(n=129)\end{array}$} \\
\hline & $M$ & $S D$ & $M$ & $S D$ & $M$ & $S D$ \\
\hline Age $^{*}$ & 41.1 & 10.0 & 27.1 & 6.4 & 30.5 & 8.2 \\
\hline Years in trade* & 17.2 & 10.0 & 6.1 & 5.4 & 7.0 & 7.3 \\
\hline Proportion of time exposed to high noise ${ }^{*}$ & $58 \%$ & $34 \%$ & $43 \%$ & $27 \%$ & $39 \%$ & $26 \%$ \\
\hline \multirow[t]{2}{*}{ Proportion of time wears HP in noise ${ }^{*}$} & $51 \%$ & $39 \%$ & $21 \%$ & $31 \%$ & $33 \%$ & $35 \%$ \\
\hline & \multicolumn{2}{|c|}{$\%(n=119)$} & \multicolumn{2}{|c|}{$\%(n=111)$} & \multicolumn{2}{|c|}{$\%(n=129)$} \\
\hline Female & \multicolumn{2}{|c|}{5.9} & \multicolumn{2}{|c|}{2.7} & \multicolumn{2}{|c|}{7.8} \\
\hline Minority & \multicolumn{2}{|c|}{10.1} & \multicolumn{2}{|c|}{16.2} & \multicolumn{2}{|c|}{13.2} \\
\hline Married* & \multicolumn{2}{|c|}{72.3} & \multicolumn{2}{|c|}{39.6} & \multicolumn{2}{|c|}{51.2} \\
\hline High school plus* & \multicolumn{2}{|c|}{30.3} & \multicolumn{2}{|c|}{46.8} & \multicolumn{2}{|c|}{65.1} \\
\hline Never use HP* & \multicolumn{2}{|c|}{10.1} & \multicolumn{2}{|c|}{44.1} & \multicolumn{2}{|c|}{20.2} \\
\hline Always use HP* & \multicolumn{2}{|c|}{11.8} & \multicolumn{2}{|c|}{1.8} & \multicolumn{2}{|c|}{2.3} \\
\hline
\end{tabular}

Note. $\mathrm{HP}=$ hearing protection.

${ }^{*} p<.001$. 
Table 2. HPM Concepts, Scales, and Reliabilities

\begin{tabular}{|c|c|c|c|c|c|}
\hline HPM Component & Scale & Description ${ }^{a}$ & Range & $M$ & $\Theta$ \\
\hline \multirow[t]{3}{*}{ Interpersonal influences } & Norms & 4 items $^{b}$ & $1-3$ & 2.2 & .76 \\
\hline & Support & 12 item ${ }^{\mathrm{b}, \mathrm{c}}$ & $1-3$ & 1.5 & .85 \\
\hline & Modeling & 2 items $^{b}$ & $1-3$ & 2.4 & .86 \\
\hline \multirow[t]{2}{*}{ Situational factors } & Availability/Access to HP & 9 items & $1-5.4$ & 3.1 & .81 \\
\hline & Noise exposure & 3 items $^{d}$ & $1-100$ & 46.8 & .94 \\
\hline Perceived control of health & Health competency & 8 items & $1.4-6$ & 3.1 & .79 \\
\hline \multirow[t]{2}{*}{ Definition of health } & Health conception-Clinical & 7 items & $1-6$ & 5.0 & .87 \\
\hline & Health conception-Overall wellness & 9 items & $1.3-6$ & 4.9 & .87 \\
\hline Perceived health & Self-rated health & 4 items $^{b}$ & $1.3-3.3$ & 2.5 & .70 \\
\hline Perceived self-efficacy & Self-efficacy in use of HP & 10 items & $1.5-6$ & 4.4 & .78 \\
\hline \multirow[t]{2}{*}{ Perceived benefits } & Benefits of HP & 12 items & $2.4-6$ & 4.6 & .73 \\
\hline & Value of use of HP & 6 items & $1-4$ & 2.6 & .88 \\
\hline Perceived barriers & Barriers to use of HP & 12 items & $1-5.6$ & 3.0 & .83 \\
\hline
\end{tabular}

aAll items, except where noted, had a 6-point Likert scale. bltems with 3 or 4 response categories. ${ }^{\text {CEight }}$ of the items in this scale were used in the analyses. dPercent of time exposed to high noise during three time periods, past week, past month, past 3 months.

Interpersonal influence, perceptions regarding others' beliefs regarding use of HPDs, was measured using three scales adapted for this study from a 28-item scale developed by the Child/Adolescent Health Behavior Research Center at the University of Michigan (Nola J. Pender, personal communication, March 16, 1993) measuring social support for exercise behavior: interpersonal norms, interpersonal support, and interpersonal modeling. Interpersonal norms was measured through questions about the respondents' beliefs about how much others (family members, friends, supervisor, and coworkers) think they should wear hearing protection. Interpersonal support was measured by a series of questions about encouragement or praise from family, friends, coworkers, and supervisors about the respondent's use of hearing protection. Interpersonal modeling was measured through two questions about how much respondents believed others use hearing protection when exposed to noise, specifically their supervisor and the coworker with whom the respondent spends the most time.

Situational factors were measured by two scales developed for this program of research. The first determined perceptions of accessibility and availability of hearing protection equipment and contained items such as "ear plugs are available to pick up at my job sites." The second scale defined high noise levels as "when you have to shout to be heard by a coworker who is 3 feet or less away from you" and asked how often they were exposed to this level of noise.

Perceived control, the extent to which the individual feels in control of his health, was measured by the Perceived Health Competence Scale (Smith, Wallston, \& Smith, 1995). An example of an item from this scale is " $I$ ' $m$ generally able to accomplish my goals with respect to my health."

Definition of health, the individual's perception of the meaning of health, was measured using a revised form of Laffrey's Health Conception Scale (Laffrey, 1986). The revision process is reported in detail elsewhere (Lusk et al., 1995); the clinical health scale was used in its original form and a new "overall wellness" subscale was created. A sample of an item from the clinical health subscale is "being free from symptoms of disease," and from the new overall wellness subscale is "feeling great—on top of the world."

Perceived health status, the individual's conception of current health, was measured by the health subindex of the Philadelphia Geriatric Center Multilevel Assessment Instrument (Lawton, Moss, Fulcomer, \& Kleban, 1982). A sample item from this scale, measured on a 4-point scale from excellent to poor, is "How would you rate your overall health at the present time?"

Perceived self-efficacy, the extent to which individuals have confidence in their ability to perform the activity, was measured by the Self-Efficacy in Use of Hearing Protection Scale developed for this program of research. An example of an item from this scale is "I am sure I can use my hearing protection so it works effectively."

Perceived benefits of use of hearing protection, beliefs regarding the positive results of the behavior, were measured by two scales developed for this program of research. The measurement of benefits of use of hearing protection was modeled on a benefit and barrier to exercise scale developed by Murdaugh \& Hinshaw (1986). A sample item for that scale is "Wearing hearing protection 
protects me against hearing loss from noise exposure." The measure for the value of use of hearing protection, modeled on Pender's value of outcome exercise scale (personal communication, Dec. 12, 1986), used a visual analogue scale to assess the degree of importance of such items as "keep out noise," or "protect my hearing."

Perceived barriers, the real or perceived impediments to engaging in the behavior, was measured by the Barriers to Use of Hearing Protection scale developed for this program of research, but modeled on the Murdaugh and Hinshaw (1986) instrument. An example of an item in this scale is "Hearing protection keeps me from hearing what I want to hear."

The latter four scales developed by the researchers and described above were reviewed by expert panels to establish construct validity. Further, in the analyses of data from factory workers, the paths from each construct to its measures were all significant beyond the .001 level, providing support for validity of all of the scales.

The dependent variable, use of hearing protection, was defined as wearing ear plugs or ear muffs. It was measured by workers' self-report of the percent of time $(0-100 \%)$ they used hearing protection during the past week, month, and 3 months when they were in high noise areas. Workers also were queried about use in high noise areas on their most recent job site and the previous job site. We have found self-report to be a reliable way to measure use of hearing protection (Lusk, Ronis, \& Baer, 1995). In the study of factory workers, three indicators of use were evaluated: self-report, observation, and supervisor report. There were several reasons why those findings supported self-report as the method of choice to determine use: (a) a high correlation of self-report and observed use $(r=$ .89); (b) a small mean difference between self-reported use and observed use (within 5\% of each other for $56 \%$ of the workers and within $10 \%$ of each other for $71 \%$ of the workers); (c) the high cost of conducting observations; and (d) the limited proportion of the total period of time that can be observed (Lusk, Ronis, \& Baer, 1995). In addition, the possibility of overestimation of use was deemed to be even less a factor for construction workers than for factory workers as they do not yet have OSHAmandated nor workplace rules regarding use of hearing protection, as do factory workers.

\section{Data Analysis}

Data were analyzed by maximum likelihood estimation of structural equation models using the EQS program (Bentler, 1989). The current analyses were conducted on the covariance matrix of 359 cases with complete data on relevant variables $(80 \%$ of the subjects in the study). Subjects excluded due to missing data were indistinguishable from those in the analyses on all variables except age, $t(443)=$ $2.96, p=.003$; clinical definition of health, $t(440)$ $=2.16, p=.031$, and wellness definition of health, $t(432)=2.07, p=.039$. The mean age for those excluded was 36.8 years and for those included was 33.0 years. Subjects included had somewhat higher scores on both the clinical definition of health (5.0 versus 4.8 on the 6-point scale) and wellness definition of health (4.9 vs. 4.7). These definitions of health variables were not significant in the causal models. Thus, loss of some cases due to missing data only slightly changed the characteristics of the sample. No particular variables accounted for the missing cases; rather, the missing data were spread evenly across the variables.

Confirmatory factor analysis (CFA) was conducted to evaluate the measurement of constructs and the strengths of correlations among them. In the CFA and the other structural equation models, the multiple item scale of each predictor construct was divided into two subscales (Marsh, Antill, \& Cunningham, 1989; Stacy, Bentler, \& Flay, 1994). These subscales were used as the measures of the constructs, allowing measurement errors for these constructs to be statistically estimated and separated from assessment of their relationships with other constructs. The remaining predictor variables (age, gender, race/ethnic group, marital status, educational level, trade group, years in trade) were measured by single items.

The dependent variable, frequency of use of hearing protection, was measured by five questions regarding the percentage of time the worker used hearing protection in two job sites and three time periods (most recent site, site before that, during past week, past month, past 3 months). Because the correlations among these items was high (ranging from .79 to .96) it was decided to average the five answers and to model this variable as if it were measured without error (rather than as a latent variable with five indicators). This approach to modeling means the relationships with use of hearing protection are slightly underestimated by the standardized path coefficients; however, the relative strength of relationships is correctly represented (Bollen, 1989). In the CFA, all factors were allowed to freely intercorrelate.

\section{RESULTS}

The confirmatory factor analysis (CFA) model was rejected as an exact fit to the data, $\chi^{2}(307)=443.6$, 
$p<.001$. In structural equation modeling, a statistically significant $\chi^{2}$ indicates that the model does not perfectly fit the data. However, because the test is sensitive to substantively unimportant departures from normality, a significant $\chi^{2}$ is almost always found unless the sample size is small (Bentler $\&$ Bonett, 1980). Because of this problem with $\chi^{2}$ test, practical measures of fit, including the normed fit index, the non-normed fit index (Bentler \& Bonnet, 1980), and the comparative fit index (Bentler, 1990) have been developed. These can all be interpreted as estimates of the proportion of variance in the covariance matrix that is explained by the model, with the comparative fit index the most accurate. Values of .9 and higher on the normed and non-normed fit indexes and .95 and higher on the comparative fit index are considered to indicate good fit (Bentler \& Bonnet, 1980; Bentler, 1990). These practical measures indicate a good fit of the CFA model (normed fit $=.92$, non-normed fit $=$ .95 , comparative fit $=.97$ ). The estimated correlation between benefits and barriers $(-.70)$, although low enough to indicate distinct constructs, was high enough to cause collinearity problems in analyses. Therefore, the benefits of use of hearing protection measure was eliminated and only the conceptually similar variable, value of use, was used to represent the HPM construct of benefit.

The revised CFA model, without the benefit scale, fit well with $\chi^{2}(265)=348.9, p<.001$, and had normed fit, non-normed fit, and comparative fit indices of $.94, .97$, and .98 , respectively. Every path from a construct to its measures was statistically significant at $p<.001$ (smallest $z=9.3$ ), providing support for the validity of the scales. The intercorrelations among the factors as estimated in the confirmatory factor analysis are shown in Table 3 . Use of hearing protection was significantly correlated with value of use, barriers to use, self-efficacy, control of health, situational factors, age, marital status, noise exposure, trade group, norm for use of hearing protection, modeling of use of hearing protection and years in the trade.

The first path model tested was the model implied by the HPM in which (a) there were direct paths to use of hearing protection from the cognitive-perceptual factors, (b) there were direct paths to the cognitive-perceptual factors from the modifying factors, but (c) there were no direct paths to use of hearing protection from the modifying factors. Although, as usual, this model could be statistically rejected with $\chi^{2}(277)=459.1, p<.001$, it had a good fit with normed fit, non-normed fit, and comparative fit of $.92, .93$, and .96 , respectively. The model accounted for $36.3 \%$ of the variance in use of hearing protection.
The statistically significant (direct or indirect) paths to use of hearing protection are shown in Figure 2. Value of use (path coefficient $=.18$ ), barriers (-.36), self-efficacy (.18), and perceived health $(-.22)$ had significant direct paths to use. Thus, other things being equal, use of hearing protection was higher among construction workers with higher perceived value of using hearing protection, lower perceived barriers, higher self-efficacy for use of hearing protection, and lower perceived health. All of these relationships were in the expected directions except for perceived health. There were no significant direct effects of health competence, or clinical or overall wellness definitions of health.

As shown in Figure 2, many of the modifying factors (experience, age, minority status, interpersonal modeling, interpersonal norms, gender, marital status, and noise exposure) had indirect paths to use of hearing protection mediated by the four significant cognitive-perceptual factors (value of use, barriers, self-efficacy, and perceived health). Age had a positive indirect path to use of hearing protection mediated by perceived value of use. This indirect path was partially offset by a negative indirect path from experience in construction work to use of hearing protection that also was mediated by perceived value of use-but the path from experience was not as strong at the path from age. Minority status had two positive indirect paths to use, one mediated by perceived value of use and one mediated by perceived barriers to use.

There was a positive indirect path from interpersonal modeling (use of hearing protection by co-workers and supervisor) to use of hearing protection mediated by perceived barriers to use. A large modification index indicated the fit of the path model would be substantially improved by allowing a direct path from interpersonal modeling to use of hearing protection. There was a mix of positive and negative indirect paths from interpersonal norms mediated by value of use (positive), barriers (positive), self-efficacy (positive), and perceived health (negative). Similarly, there were both positive and negative indirect paths from female gender, mediated by self-efficacy and by perceived health.

There were no statistically significant paths from the other modifying factors: education, trade, or social support. The hypothesized direct paths to use from control of health and clinical and wellness definitions of health were statistically nonsignificant, and a large modification index suggested the addition of a direct path to use from the modifying factor of interpersonal modeling.

Exploratory analyses were conducted to deter- 


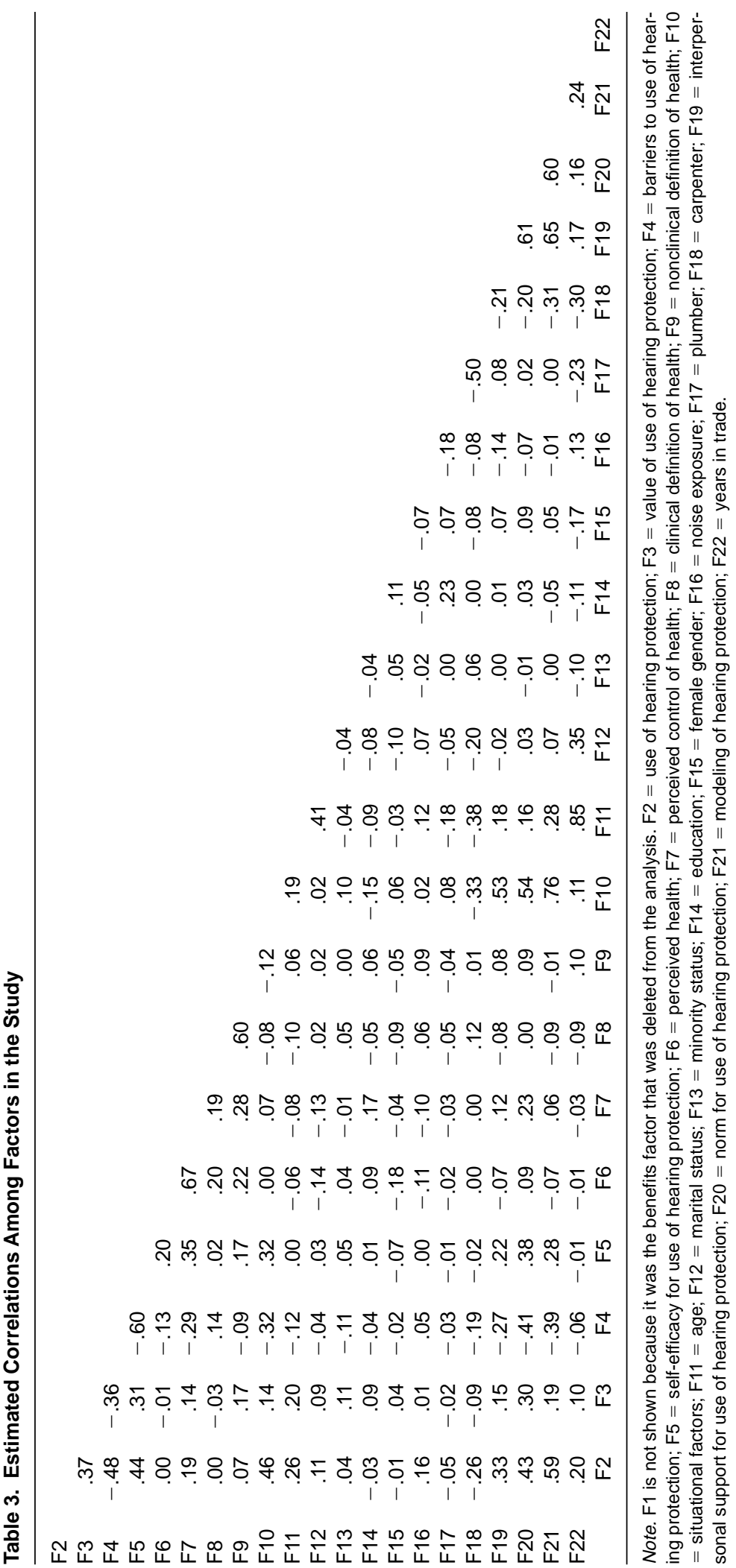




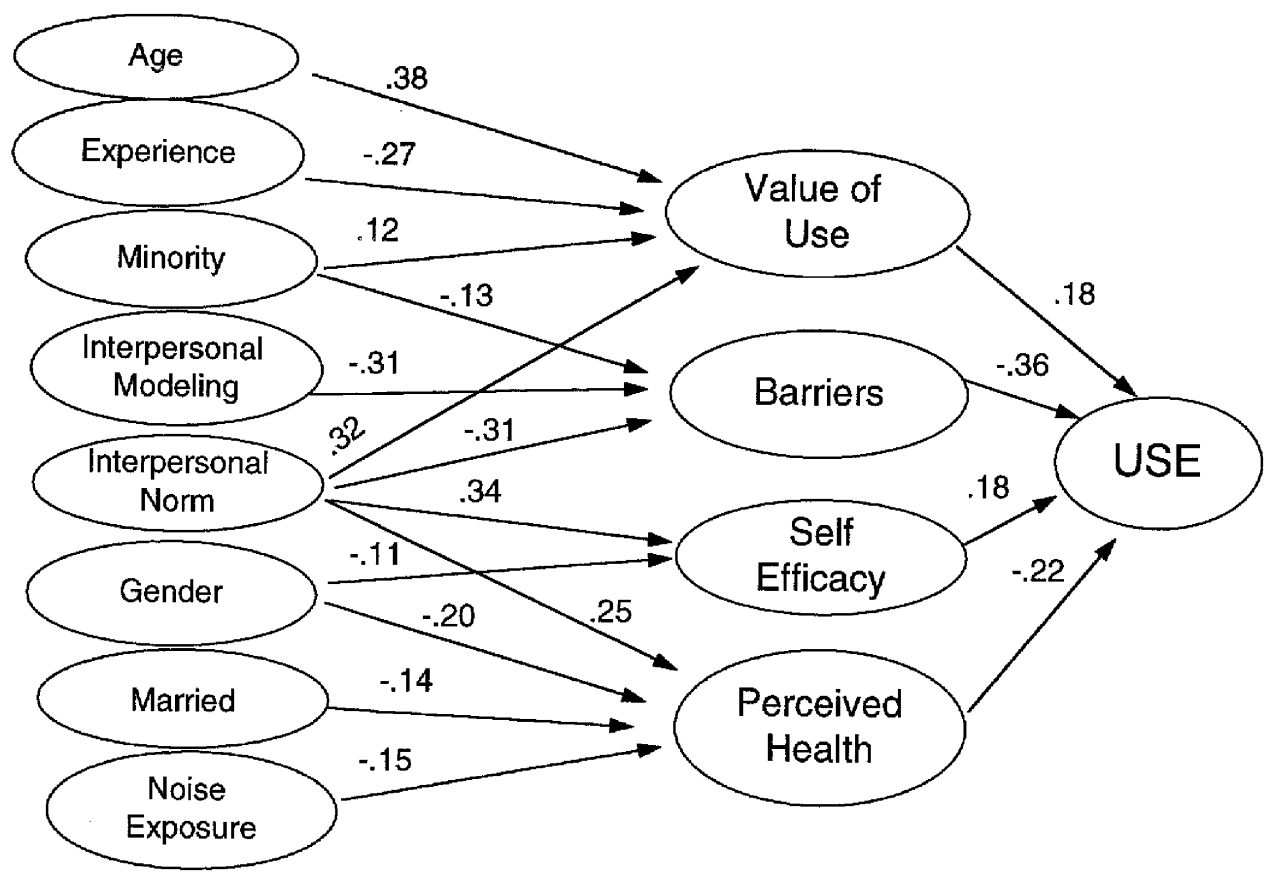

FIGURE 2. Standardized path model showing estimated paths from the theoretical model. Relationships shown are statistically significant at $p<.05$. Constructs not included did not have significant direct or indirect paths to use. For simplicity, noncausal correlations among constructs are not shown.

mine which factors had direct paths to use of hearing protection and as a further test of the HPM. Two steps were taken in this exploratory path analysis: (a) a model was estimated in which all predictors had direct paths to use and were allowed to intercorrelate; and (b) paths were deleted and added until all included paths were significant and the modification indices indicated no more should be added. This step is analogous to a stepwise regression of use on all predictors. This model fit extremely well (normed fit $=.93$; nonnormed fit $=.97$; comparative fit $=.98)($ Bentler $\&$ Bonnet, 1980; Bentler, 1990). This exploratory model accounted for $50.6 \%$ of the variance in use of hearing protection, substantially more than explained by the theoretical model.

As shown in Figure 3, three of the predictors in the theoretical model (value of use, barriers, and self-efficacy) and two additional ones (interpersonal modeling and noise exposure) had significant direct paths to use. The modifying factor of interpersonal modeling accounted for notably more of the variance in use than any of the other predictors. The other significant predictors (value of use, barriers, self-efficacy, and noise exposure) were all of about equal importance. In this model, high use of hearing protection is predicted by high perceived value of use, low perceived barriers to use, high self-efficacy for use, frequent noise exposure, and especially by high interpersonal modeling of use.

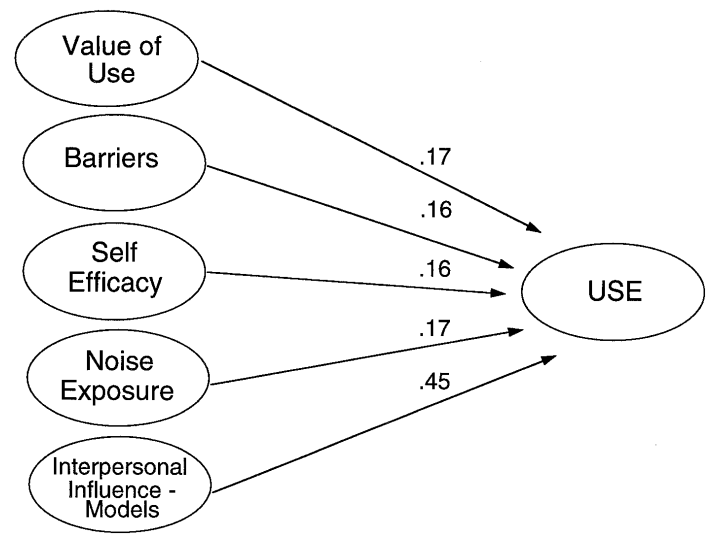

FIGURE 3. Standardized path model showing estimated paths from the exploratory model. Relationships shown are statistically significant at $p<.05$. Constructs not included did not have significant direct paths to use. 


\section{DISCUSSION}

In this test of the health promotion model, a comparison of the results from the testing of the theoretical model and the exploratory model proved useful. In both models, three cognitive-perceptual factors, benefits (value of use), barriers, and self-efficacy, had significant direct paths to use, with the expected signs. An additional cognitive-perceptual factor, perceived health, was also an important predictor in the theoretical model. In the exploratory model, when modifying factors were allowed to directly relate to use, two of these factors (interpersonal modeling and noise exposure) became important predictors. Pender's (1996) revision of the HPM (Figure 4) includes the modifying factors, situational factors and demographic characteristics, as having a direct influence on behavior. Thus, findings from the exploratory model with this sample are consistent with that aspect of the revised model. Further, the substantial differences in the amount of variance explained between the theoretical and exploratory models also supports the revision of the HPM to allow modifying factors to relate directly to the behavior.

The majority of the significant predictors in the theoretical and the exploratory models (value of, barriers to, self-efficacy of, and interpersonal influences on the use of hearing protection) were those variables that were specific to the behavior measured by the dependent variable. The only general cognitive-perceptual variable with a significant path was perceived health status, and only in the theoretical model. These results also are consistent with the revised HPM, which proposes that it is the behavior-specific influences that have strong direct paths to behavior (Pender, 1996).

Consistency in tests of the HPM has now been found in six different samples: (a) in Pender's (Pender et al., 1990) program of research with four different samples, four variables (benefits, barriers, self-efficacy, and perceived health status) were the important predictors; (b) in a study of factory workers (Lusk et al., 1994) three of these same components of the HPM were important predictors (benefits, barriers, and self-efficacy), but the fourth component was control of health (called health competence in the present study) rather

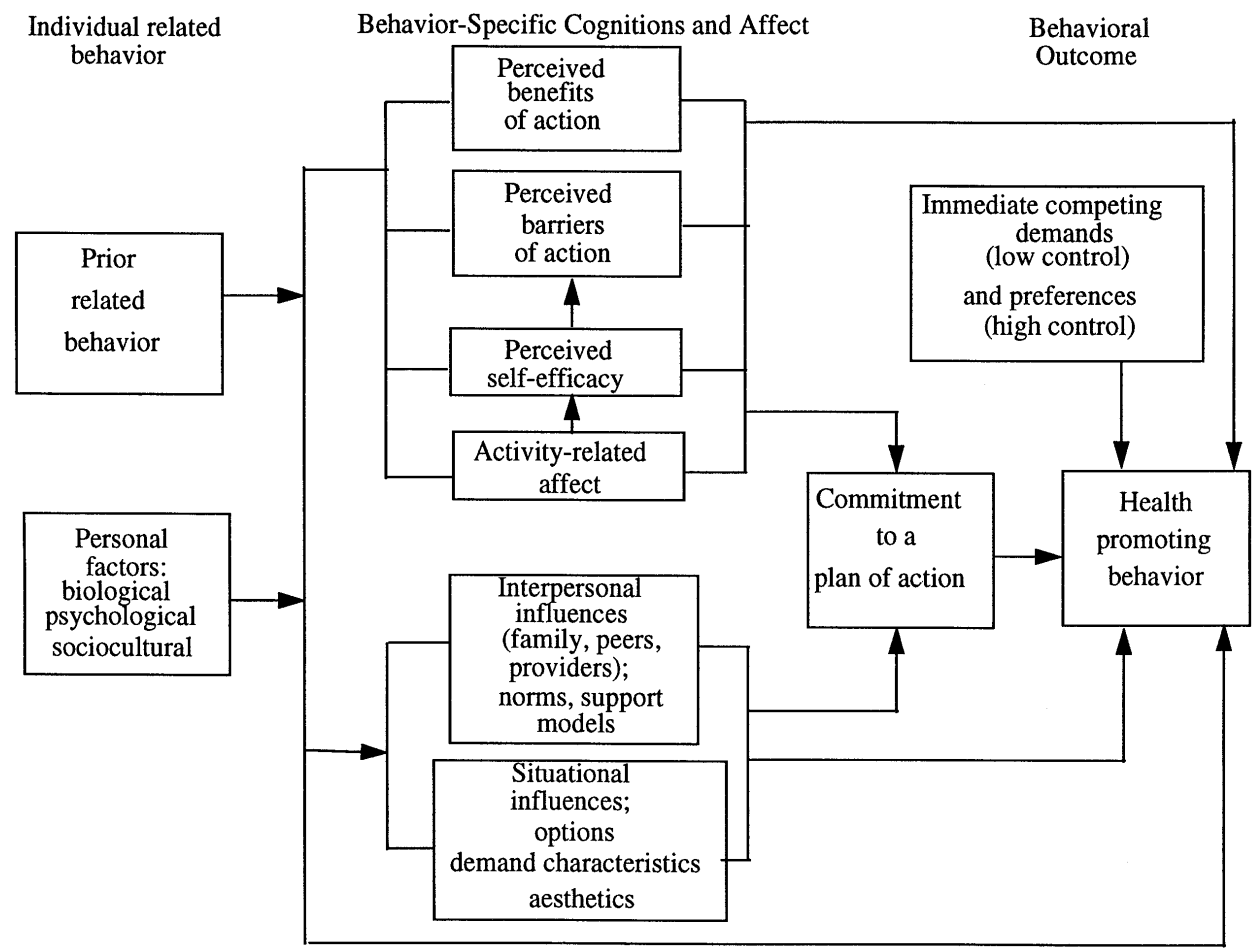

FIGURE 4. Pender's revised health promotion model. From Health promotion in nursing practice (3rd ed., p. 67), by N.J. Pender, 1996, Stamford, CT: Appleton \& Lange. Used with permission. 
than perceived health; (c) in this current study of construction workers in the test of the theoretical model, the same four components of the HPM were important predictors as in the Pender samples. Thus, considerable stability in the results of test of the HPM has been demonstrated despite the contrary results of Johnson et al. (1993), and Ratner et al. (1994). However, it should be noted that for both the factory workers and the construction workers, the measures of perceived health status and perceived health competence, respectively, were negatively related to the behavior.

Because both of these samples were predominantly male, hypotheses regarding gender differences in health and mortality may help to explain these results. Men feel more mastery in their lives (therefore feeling more in control of their health) (Verbrugge, 1989); are less likely than women to attend to, share information about, or recall illness or health problems (therefore reporting higher perceived health status) (Verbrugge, 1985); and are less likely to take preventive action (Verbrugge \& Wingard, 1987). Thus, these characteristics associated with men may explain the unexpected relationship of perceived health status with use of hearing protection, a preventive behavior.

The HPM could be expected to predict specific behaviors better than general health habits. Likewise, those components of the HPM measuring specific behaviors are the ones that have been the best predictors. Pender (1996) emphasizes the importance of behavior-specific components of the revised HPM and also suggests direct relationships between the former modifying factors and the specific behavior; this is supported by the findings from this study and the previous study of factory workers (Lusk et al., 1994).

The HPM's ability to predict behavior has been supported. However, further tests of the HPM are needed, especially as not all of the components of the HPM have been fully tested. In the current study, interpersonal influences, which had not been tested with factory workers, were found to be strong predictors of hearing protection use. Two factors in the former HPM-biological characteristics and behavioral factors-were not measured. In addition, the revised HPM (Pender, 1996) includes several new components which have not been operationalized or measured.

In the first test of the HPM as a causal model for factory workers' use of hearing protection (Lusk et al., 1994), guarded optimism was expressed regarding its relevance to this behavior. After obtaining nearly identical results with an entirely different group (construction workers), greater confidence can be placed in this model's ability to predict use of hearing protection. The identified predictors have provided the bases for an intervention currently being tested for effectiveness in increasing construction workers' use of hearing protection.

Though the HPM is a causal model, structural equation modeling with cross-sectional data provides no evidence about the directions of causality among variables. [See Heath et al. (1993) for exceptions involving behavioral genetic research designs such as twin studies.] Some alternative models, including a model with all causal paths reversed, would fit the data equally well. Longitudinal studies and tests of theory-based interventions, such as the one we are currently conducting, are needed to provide evidence of the directions and causal nature of these paths.

\section{REFERENCES}

Abel, S.M., Alberti, P.W., Haythornthwaite, C., \& Riko, K. (1982). Speech intelligibility in noise: Effects of fluency and hearing protector type. Journal of the Acoustical Society of America, 71, 708-715.

Bentler, P.M. (1989). EOS structural equations program manual. Los Angeles: BMDP Statistical Software.

Bentler, P.M. (1990). Comparative fit indexes in structural models. Psychological Bulletin, 107, 238-246.

Bentler, P.M., \& Bonett, D.C. (1980). Significance tests and goodness of fit in the analysis of covariance structures. Psychological Bulletin, 88, 588-606.

Berger, E.H. (1980). The effects of hearing protectors on auditory communications. Occupational Health Nursing, 28(1), 6-7.

Bollen, K.A. (1989). Structural equations with latent variables. New York: Wiley.

Cohen, S., \& Weinstein, N. (1981). Nonauditory effects of noise on behavior and health. Journal of Social Issues, 37(1), 36-70.

DeJoy, D.M. (1984). The nonauditory effects of noise: Review \& perspectives for research. Journal of Auditory Research, 24, 123-150.

Heath, A.C., Kessler, R.C., Neale, M.C., Hewitt, J.K., Eaves, L.J., \& Kendler, K.S. (1993). Testing hypotheses about direction of causation using cross-sectional family data. Behavior Genetics, 23, 29-50.

Johnson, J.L., Ratner, P.A., Bottorff, J.L., \& Hayduk, L.A. (1993). An exploration of Pender's health promotion model using LISREL. Nursing Research, 42, 132-138.

Laffrey, S.C. (1986). Development of a health conception scale. Research in Nursing \& Health, 9, 107-113.

Langlie, J.K. (1977). Social networks, health beliefs, and preventive health behavior. Journal of Health and Social Behavior, 18, 244-260.

Lawton, M.P., Moss, M., Fulcomer, M., \& Kleban, M.H. 
(1982). A research and service oriented multilevel assessment instrument. Journal of Gerontology, 37, 91-99.

Lusk, S.L., Kerr, M.J., \& Baer, L.M. (1995). Psychometric testing of the reduced Laffrey Health Conception Scale. American Journal of Health Promotion, 9 , 220-225.

Lusk, S.L., Kerr, M.J., \& Kauffman, S.A. (1996). Use of hearing protection and perceptions of noise exposure among construction workers. Manuscript in preparation.

Lusk, S.L., Ronis, D.L., \& Baer, L.M. (1995). A comparison of multiple indicators: Observations, supervisor report, and self-report as measures of workers' hearing protection use. Evaluation and the Health Professions, 18, 51-63.

Lusk, S.L., Ronis, D.L., Kerr, M.J., \& Atwood, J.R. (1994). Test of the Health Promotion Model as a causal model of workers' use of hearing protection. Nursing Research, 43, 151-157.

Marsh, H.W., Antill, J.K., \& Cunningham, J.D. (1989). Masculinity and femininity: A bipolar construct and independent constructs. Journal of Personality, 57, 625-663.

Murdaugh, C., \& Hinshaw, A.S. (1986). Theoretical model testing to identify personality variables effecting preventive behaviors. Nursing Research, 35, 19-23.

National Institute for Occupational Safety and Health. (1996). National occupational research agenda. Washington, DC: U.S. Department of Health \& Human Services, Public Health Service, Center for Disease Control and Prevention.

Occupational Safety and Health Administration. (1981, Jan 16). Occupational noise exposure: Hearing conservation amendment (OSHA Publication No. 29 CFR 1910). Federal Register, 46(11). Washington, DC: U.S. Government Printing Office.

Pender, N.J. (1987). Health promotion in nursing practice (2nd ed.). Norwalk, CT: Appleton \& Lange.

Pender, N.J. (1996). Health promotion in nursing practice (3rd ed.). Stamford, CT: Appleton \& Lange.

Ratner, P.A., Bottorff, J.L., Johnson, J.L., \& Hayduk, L.A. (1994). The interaction effects of gender within the Health Promotion Model. Research in Nursing \& Health, 17, 341-350.

Sataloff, R., \& Sataloff, R.T. (1986). Documenting hearing conservation test equipment's effectiveness. Occupational Health and Safety, 55(2), 28, 29, 32-33, 35-36.

Savell, J.F., \& Toothman, E.H. (1987). Group mean hearing threshold changes in a noise-exposed industrial population using personal hearing protectors. American Industrial Hygiene Association Journal, 48, 23-27.

Sloan, R.P. (1991). Cardiovascular effects of noise. In T.H. Fay (Ed.), Noise \& health (pp. 15-26). New York: New York Academy of Medicine.

Smith, M.S., Wallston, K.A., Smith, C.A. (1995 Mar). The development and validation of the Perceived Health Competence Scale. Health Education Resource, 10(1), 51-64.

Stacy, A.W., Bentler, P.M., \& Flay, B.R. (1994). Attitudes and health behavior in diverse populations: Drunk driving, alcohol use, binge eating, marijuana use, and cigarette use. Health Psychology, 13(1), 73-85.

Strecher, V.J., Becker, M.H., Kirscht, J.P., Eraker, S.A., \& Graham-Tomasi, R.P. (1985). Psychosocial aspects of changes in cigarette-smoking behavior. Patient Education and Counseling, 7, 249-262.

United States Bureau of the Census. (1995). Statistical abstract of the United States (115th ed.). Washington, DC: United States Government Printing Office.

van Dijk, F.J.H., Souman, A.M., \& de Vries, F.F. (1987). Non-auditory effects of noise in industry. VI. A final field study in industry. International Archives of Occupational and Environmental Health, 59, 133-145.

Verbrugge, L.M. (1985). Gender and health: An update on hypotheses and evidence. Journal of Health and Social Behavior, 26, 156-182.

Verbrugge, L.M. (1989). The twain meet: Empirical explanations of sex differences in health and mortality. Journal of Health and Social Behavior, 30, 282-304.

Verbrugge, L.M., \& Wingard, D.L. (1987). Sex differentials in health and mortality. Women \& Health, 12(2), 103-145. 